\title{
Antara Teks dan Praktik: Ritual Iomante pada Cerita Rakyat Ainu Jepang
}

\author{
Ida Ayu Laksmita Sari \\ Prodi Sastra Jepang, Fakultas Ilmu Budaya, Universitas Udayana \\ Jalan Pulai Nias No. 13 Denpasar, Bali 80114, Indonesia \\ dayumita23@gmail.com
}

\begin{abstract}
Masyarakat Ainu, penduduk asli Jepang yang selama ratusan tahun sempat termaginalkan, kaya akan budaya yang terus dilestarikan antara lain melalui aktivitas ritual dan cerita rakyat. Salah satu ritual penting yang muncul berulang dalam cerita rakyat Ainu adalah iomante (iyomante), ritual pengembalian arwah beruang ke alam dewa. Makalah ini menganalisis hubungan antara praktik ritual dengan teks cerita tentang iomante. Analisis difokuskan pada bagaimana ritual iomante dilukiskan dalam cerita rakyat, mengapa iomante muncul berulang dalam cerita-cerita rakyat Ainu, dan apa hubungan antara cerita rakyat iomante dengan praktik ritual iomante yang digelar masyarakat Ainu dewasa ini. Objek dari penelitian ini diambil dari cerita rakyat yang terkumpul dalam buku antologi cerita rakyat Ainu Ainu Mukashi Banashi: Hitotsubu no Satciporo dengan editor Kayano Shigeru (1993). Data dikaji dengan teori sosiologi sastra dan teori semiotika. Teori sosiologi sastra menganalisis cerita sebagai refleksi kehidupan sosial budaya masyarakat, sedangkan teori semiotika digunakan untuk mengkaji simbol-simbol dalam cerita rakyat secara denotatif, konotatif dan mitos atau ideologi. Makalah ini menyimpulkan bahwa pelukisan ritual iomante dalam cerita rakyat Ainu menjadi wadah bagi masyarakat untuk ideologisasi tradisi budaya, sementara praktik ritual iomante dewasa ini mengalami penambahan fungsi dari sebatas fungsi spiritual dengan fungsi festival, khususnya ketika ritual dipromosikan sebagai daya tarik pariwisata etnik yang dikembangkan masyarakat Ainu.
\end{abstract}

Kata kunci: ritual iomante, cerita rakyat ainu, ideologi, pariwisata etnik

\section{Between Text and Practices: Iomante Ritual in Ainu Folktales in Japan}

The Ainu people, indigenous Japanese who have been marginalized for hundreds of years, are rich in culture that continues to be preserved, among others, through ritual activities and folklore. One important ritual that appears repeatedly in Ainu folklore is iomante (iyomante), the ritual of returning bear spirits to the deva realm. This paper analyzes the relationship between ritual practice and the story text about iomante. The analysis focuses on how iomante rituals are depicted in folklore, why iomante appears repeatedly in Ainu folktales, and what is the connection between iomante folklore and the practice of iomante rituals held by today's Ainu communities. The object of this research is taken from folklore collected in the anthology of Ainu folktales titled Ainu Mukashi Banashi: Hitotsubu no Satcipporo edited by Kayano Shigeru (1993). The data is examined by the sociological theory of literature and the theory of semiotics. Literary sociology theory analyzes the story as a reflection of the socio-cultural life of the community, while the semiotic theory is used to examine the symbols in folklore denotatively, connotatively and mythically or ideologically. This paper concludes that the depiction of iomante ritual in Ainu folklore serves as a forum for people to ideologize cultural traditions, while today's iomante ritual practices experience additional functions than limited to spiritual functions with festival functions, especially when rituals are promoted as ethnic tourism attractions developed by Ainu people .

Keywords: iomante ritual, ainu folklore, ideology, ethnic tourism

Proses Review : 1 - 18 April 2019, Dinyatakan Lolos: 22 April 2019 


\section{PENDAHULUAN}

Masyarakat Ainu adalah penduduk asli (indigenous) Jepang yang secara historis dan dominan tinggal di Hokkaido, Jepang Utara. Etnik Ainu memiliki banyak tradisi lisan, seperti lagu dan cerita rakyat (Strong, 2011; Davidson, 2007; Batchelor, 1898; 1892; 1901). Cerita rakyat Ainu banyak mengisahkan hubungan manusia dengan dewa ('kamui'), terutama dalam konteks ritual yang merupakan cermin dari sistem kepercayaan mereka. Dalam sistem kepercayaan masyarakat Ainu, beruang merupakan kamui dengan kedudukan tertinggi. Beruang secara fisik memiliki kekuatan yang lebih besar daripada manusia dan bisa bertahan hidup dalam musim dingin hanya dengan menjilat garam di cakarnya. Ohnuki-Tierney (1981:83) menyebutkan bahwa karena kekuatan dan kapasitasnya itulah beruang dianggap sebagai dewa tertinggi seperti kutipan berikut:

The highest deity that determines Ainu welfare, if they are happy, they give abundantly food and protect the Ainu ... but if offended they can punish humans by hurting them.

\section{Terjemahan:}

Dewa tertinggi yang menentukan kesejahteraan Ainu, jika mereka bahagia, mereka memberi berlimpah makanan dan melindungi Ainu ... tetapi jika tersinggung mereka dapat menghukum manusia dengan menyakiti mereka.

Selain menyebutkan beruang sebagai kamui tertinggi, kutipan di atas juga menegaskan bahwa beruang sebagai kamui dapat menolong manusia yang melindunginya dan menghukum yang menyakitinya. Sadar akan kemahakuasaan beruang, masyarakat Ainu senantiasa memujanya melalui berbagai ritual. Salah satu yang terkenal adalah iomante, upacara pengembalian roh beruang ke alam dewa. Upacara iomante merupakan upacara terpenting dalam sistem kepercayaan Ainu. Kitagawa menyebutkan bahwa upacara ini "the supreme act of the Ainu community transmitted from the remote past to the present time" (1961:151), artinya upacara iomante merupakan pemujaan tertinggi etnink Ainu yang dilaksanakan sejak silam sampai masa kini. Mengingat upacara ini berisi adegan membunuh beruang maka bagi yang tidak paham upacara menganggap hal ini kejam dan barbar (Fitzhugh, 1999:25-26; Sjöberg, 2013:53). Pemerintah Jepang pernah melarang dengan alasan politik akulturasi, artinya agar warga Ainu pelan-pelan meninggalkan kebudayaannya dan bergabung dengan Jepang (Sjöberg, 2013:78). Bagi Ainu, bukan pembunuhan yang penting, tetapi pengembalian roh beruang ke alam Dewa sebagai bentuk pemujaan dan memohon perlindungan (Utagawa, 1999:256-257; Renner, 2012:213). Kalaupun kemudian iomante diperbolehkan, namun dalam pelaksanaannya tidak diizinkan membunuh beruang. Namun, masyarakat Ainu demikian bangga dan lekat dengan budayanya sehingga ritual itu tetap dilaksanakan walau dengan diam-diam dan tetap memakai beruang (Sjöberg,
2013:78).

Kajian terhadap ritual iomante mendapat perhatian banyak sarjana sejak lama, khususnya kalangan antropologi dan bidang studi budaya lainnya. Daya tarik terhadap Ainu terjadi karena mereka memiliki budaya yang unik dan kontroversi karena dilarang oleh pemerintah Jepang. Peneliti etnik dan budaya Ainu khususnya iomante seperti Sjöberg (2013) dalam buku The Return of the Ainu Cultural Mobilization and the Practice of Ethnicity in Japan menguraikan kembalinya budaya Ainu dengan pendekatan etnografi. Ritual iomante menempati posisi penting dalam budaya Ainu dan mendapat kajian yang komprehensif dalam buku ini.

Kajian mengenai iomante bisa dibaca dari penelitian Kitagawa (1961), Akino (1999), Kindaichi (1999), Fitzhugh (1999), Utagawa (1999). Kitagawa (1961) membahas iomante dari sudut religius yang mengatakan bahwa iomante adalah upacara utama etnik Ainu, Akino (1999) membahas proses pelaksanaan ritual, Kidaichi (1949) membahas berbagai konsep di balik pelaksanaan iomante. Fitzhugh (1999) membahas iomante dalam konteks sejarah Ainu, Utawaga (1999) menelusuri sejarah iomante, sedangkan Renner (2012) membahas aspek tari dan musik masyarakat Ainu termasuk dalam iomante. Dari beberapa studi yang ada, belum ada yang membahas iomante dari cerita rakyat Ainu.

Artikel ini menganalisis bagaimana cerita rakyat Ainu mengisahkan upacara iomante dan hubungannya dengan dewa beruang dan manusia. Juga dibahas mengenai mengapa iomante muncul berulang dalam cerita-cerita rakyat Ainu, dan apa hubungan antara cerita rakyat iomante dengan praktik ritual iomante yang digelar masyarakat Ainu dewasa ini. Berbeda dengan penelitian sebelumnya, artikel ini diharapkan memberikan kontribusi dalam pemahaman iomante melalui folktales, salah satu kekayaan tradisi lisan Ainu.

\section{METODE DAN TEORI}

Artikel ini menggunakan pendekatan analisis kualitatif dengan menjadikan cerita rakyat Ainu yang mengisahkan tentang ritual iomante sebagai data primer. Data sekunder diambil dari rekaman video dan foto-foto tentang iomante, serta kajian tentang pelaksanaan iomante oleh masyarakat Ainu dewasa ini. Kajian difokuskan pada bagaimana cerita rakyat mengisahkan mengenai iomante dan mengapa cerita dengan tema ini muncul dalam beberapa cerita, serta apa arti kehadiran tema cerita iomante dalam korpus cerita rakyat Ainu? Sumber data primer adalah Ainu Mukashi Banashi: Hitotsubu no Satciporo (1993) yang dikumpulkan oleh Shigeru Kayano. Kayano adalah budayawan dan tokoh Ainu yang pertama kali menjadi anggota parlemen Jepang (Sjöberg, 2013:236). Sebagai tokoh Ainu dan anggota parlemen, dia memiliki kemampuan untuk mem- 
bela dan melestarikan budaya sukunya, seperti dilakukan melalui membukukan cerita rakyat yang dimiliki. Dokumen foto dan audio visual iomante berjudul "The Ainu Bear Ceremony" yang dibuat antropolog Dr. N.G. Munro dianalisis untuk melihat kemiripan antara teks cerita dengan praktik ritual iomante.

Data primer dianalisis dengan teori sosiologi sastra, sebuah pendekatan sosial terhadap sastra yang memiliki tiga fokus. Ketiga fokus itu adalah kajian teks sastra sebagai cermin kehidupan masyarakat atau dokumen sosial, kajian terhadap latar belakang sosial pengarang sebagai pencipta, dan kajian terhadap tanggapan pembaca terhadap karya sastra (Teeuw, 1984; Damono, 1978). Mengutip pendapat Grebstein, Damono menyatakan bahwa pemahaman terhadap karya sastra tidak bisa dipisahkan dari latar belakang sosial penciptaannya. Artinya, pemahaman akan latar belakang sosial masyarakat saat cerita diciptakan sangat penting dalam pemahaman karya sastra (Damono, 1978:4-5). Dalam makalah ini, kajian dilakukan terhadap teks sastra cerita rakyat sebagai refleksi kehidupan sosial masyarakat Ainu dan bagaimana masyarakat Ainu generasi dewasa ini menerima dan memaknai cerita rakyat tentang iomante itu. Dengan kata lain, kajian difokuskan pada cerita rakyat sebagai dokumen sosial atau cermin kehidupan sosial masyarakat.

Penerimaan dan pemaknaan cerita rakyat tentang iomante dikaji dengan teori semiotik Roland Barthes (1962; 1977) yang memusatkan pemaknaan dalam tiga level yaitu denotatif, konotatif, dan mitos (ideologis). Level terakhir ini bisa disebut dengan metasemiotik karena pemaknaan yang berkaitan dengan latar belakang sosial, budaya, geografi, politik yang kompleks (Chandler, 2022:143). Pemaknaan denotatif artinya pemaknaan tanda dalam teks secara harfiah, mengacu arti kata seperti literal, natural atau seperti dalam kamus; pemaknaan konotatif adalah memperhatikan makna kiasan yang melebihi makna pertama (denotatif); sedangkan pemaknaan mitos atau mitologisasi adalah pemberian makna terhadap karya sastra yang berkaitan dengan world view atau pandangan dunia (Chandler, 2002:144). Pandangan dunia dalam konteks analisis ini berkaitan dengan sistem kepercayaan masyarakat Ainu sebagai pemilik cerita rakyat. Analisis diawali dengan kajian antara pelaksanaan ioamante dan representasi dalam teks.

\section{TEKS CERITA IOMANTE SEBAGAI CERMIN SOSIAL BUDAYA AINU}

Ritual iomante dengan berbagai aspeknya merupakan salah satu tema yang muncul berulang dalam cerita rakyat Ainu. Teks-teks cerita yang ada mengisahkan tentang pelaksanaan iomante dengan narasi yang mirip dengan yang didokumentasi dalam bentuk lain, seperti foto dan audio visual. Teks-teks cerita rakyat tentang iomante dapat dikatakan sebagai cermin kehidupan atau dokumen sosial budaya Ainu.

Pembacaan secara seksama dan berulang-ulang terhadap cerita-cerita dalam antologi Ainu Mukashi Banashi: Hitotsubu no Satciporo yang disunting oleh Shigeru Kayano menemukan empat buah cerita yang mengkisahkan tentang iomante. Kisah yang ditulis dalam bahasa Jepang ini menarasikan tentang pengiriman arwah beruang ke alam atau negeri dewa. Lukisan-lukisan itu tampil dalam intensitas yang berbeda, artinya ada yang secara langsung atau tidak langsung melukiskan prosesi upacara iomante ada juga yang hadir sebagai subtema. Keempat cerita tersebut, yaitu Hima na Konabe, Bimbou Ainu to Yukar, Monoshiri Roujin, dan Mimiwa no Katahou (Lihat Tabel).

Karakteristik cerita rakyat Ainu adalah kecenderungan memakai nama tokoh tanpa nama yang konvensional, tetapi nama kategoris misalnya 'orang tua'. Dilihat dari point of view (sudut pandang) narasi, cerita rakyat Ainu menggunakan sudut pandang orang pertama tunggal, biasanya memakai nama 'aku'. Kata 'aku' itu bisa mengacu kepada orang atau binatang, seperti 'beruang', atau benda dalam hal bahwa benda itu adalah jelmaan binatang. Ciri lainnya terletak pada alur yang menggunakan model sorot balik (flashback), membuat cerita rumit tetapi menarik. Cerita rakyat Ainu menggunakan latar alam yang kental, dengan deskripsi yang fungsional, misalnya sungai, laut, gunung sebagai tempat berburu atau menangkap ikan (Sari, 2019). Ciri penggunaan sudut pandang, nama tokoh, dan alur yang rumit, bolak-balik, flashback itu bisa disimak dalam cerita dalam tabel.

Dalam kisah Hima na Konabe ('Panci Kecil yang Memiliki Waktu Luang'), Dewa Beruang dituturkan lewat sudut pandang tokoh utama, yaitu Dewa Beruang itu sendiri. Dewa Beruang tersebut menceritakan sendiri bagaimana ia secara suka rela datang ke negeri manusia untuk sengaja menyerahkan diri agar manusia dapat menangkap dan memakan dagingnya.

わたしも、かねてうわさに聞いていた石狩川の上流 に住むアイヌのところへ揢になって行こうと思 い、ある日のこと、ゆっくりゆっくり山を降りまし た。うわさに聞いていた精神のいいアイヌが、狩り のためにわたしの住まい近くにきているのが見えた からです。わたしはわざと、そのアイヌに見られる ようにでて行くと、アイヌはさっと立ち杖うしろ にかくれ、弓に矢をつがえて持っていました (Kayano, 1993:29).

Terjemahan:

Aku (Dewa Beruang) juga memutuskan untuk pergi ke hulu Sungai Ishikari tempat Ainu (manusia) itu tinggal, pada suatu hari aku turun dari gunung perlahan-lahan. Aku pun melihat manusia yang baik seperti yang aku dengar sebelumnya. Manusia itu datang ke dekat tempat tinggal aku untuk berburu. Aku pun sengaja ke luar ke tempat yang 
Tabel. Cerita Rakyat Ainu mengenai Ritual Iomante

\begin{tabular}{|c|c|c|c|}
\hline No. & Judul & Inti Cerita & Deskripsi mengenai Iomante \\
\hline 1 & $\begin{array}{l}\text { Hima na Konabe } \\
\text { ('Panci Kecil yang Memiliki } \\
\text { Waktu Luang') }\end{array}$ & $\begin{array}{l}\text { Seekor beruang ditangkap dan dibuat- } \\
\text { kan upacara iomante. Pada upacara itu } \\
\text { hadir pula Dewa Panci yang berubah } \\
\text { menjadi anak laki-laki yang pandai } \\
\text { menari. }\end{array}$ & $\begin{array}{l}\text { Dewa Beruang dan } \\
\text { Dewa Panci (kecil) bermurah } \\
\text { hati membantu manusia dalam } \\
\text { melaksanakan upacara iomante. }\end{array}$ \\
\hline 2 & $\begin{array}{l}\text { Bimbou Ainu to Yukar } \\
\text { ('Manusia Ainu yang Miskin } \\
\text { dan Cerita Saga') }\end{array}$ & $\begin{array}{l}\text { Laki-laki miskin tidak pandai berbu- } \\
\text { ru, tetapi pandai bercerita tentang } y u \text { - } \\
\text { kar ('saga') sehingga membuat Dewa } \\
\text { Penyakit pergi dari desanya. Dewa } \\
\text { yang diberikan persembahan oleh la- } \\
\text { ki-laki itu memberikan hadiah tempat } \\
\text { menyimpan rokok. Laki-laki itu pun } \\
\text { menjadi pandai berburu dan hidupnya } \\
\text { berubah. }\end{array}$ & $\begin{array}{l}\text { Karena kebaikan tokoh laki-laki, Dewa } \\
\text { Penyakit pergi dari desa dan member- } \\
\text { ikan laki-laki itu hadiah. Dewa berpe- } \\
\text { san agar ia terus mempersembahkan } \\
\text { yukar pada setiap upacara, khususnya } \\
\text { ketika mengirimkan kembali arwah } \\
\text { beruang ke negeri dewa (iomante). }\end{array}$ \\
\hline 3 & $\begin{array}{l}\text { Monoshiri Roujin } \\
\text { ('Orang Tua yang Serba } \\
\text { Tahu') }\end{array}$ & $\begin{array}{l}\text { Seorang istri meminta suaminya un- } \\
\text { tuk menikah lagi demi mendapatkan } \\
\text { keturunan. Mereka memelihara see- } \\
\text { kor beruang kecil yang ternyata ada- } \\
\text { lah siluman kappa dan berhasil dika- } \\
\text { lahkan oleh orang tua yang serba tahu. }\end{array}$ & $\begin{array}{l}\text { Kappa (katak siluman) bersiluman } \\
\text { lagi menjadi beruang agar bisa } \\
\text { berinteraksi dekat dengan manusia } \\
\text { yang hendak dimangsanya. Tokoh } \\
\text { memelihara anak beruang dengan } \\
\text { tujuan melaksanakan ritual iomante. } \\
\text { Bersyukur belangnya diketahui oleh } \\
\text { orang tua yang mahatahu. }\end{array}$ \\
\hline 4 & $\begin{array}{l}\text { Mimiwa no Katahou } \\
\text { ('Sebelah Bagian Ant- } \\
\text { ing-Anting') }\end{array}$ & $\begin{array}{l}\text { Seorang anak laki-laki menyelamat- } \\
\text { kan beberapa penduduk dari bahaya } \\
\text { beruang yang mengamuk. }\end{array}$ & $\begin{array}{l}\text { Dewa Beruang yang berkedudukan } \\
\text { tinggi menjadi dewa yang melakukan } \\
\text { pengerusakan di dunia manusia. Dewa } \\
\text { sebagai dewa tertinggi yang baik hati } \\
\text { dalam kepercayaan ainu dapat berbuat } \\
\text { onar jika persembahan kepadanya ti- } \\
\text { dak dilakukan semestinya }\end{array}$ \\
\hline
\end{tabular}

terlihat manusia itu, manusia itu pun segera bersembunyi di balik pohon dan bersiap memegang anak panah.

Struktur cerita menunjukkan bahwa di bagian awal cerita Hima na Konabe terlihat tokoh "aku" merupakan Dewa Beruang yang turun dari gunung menghampiri tempat tinggal manusia. Dalam kepercayaan masyarakat Ainu, Dewa Beruang tidak sembarangan menampakkan diri. Walker (2001:78) berpendapat bahwa cerita rakyat Ainu sering menekankan bahwa beruang hanya mau muncul di hadapan tokoh pemburu yang baik, yang memiliki karakter moral tinggi dan sering melakukan ritual untuk para dewa. Untuk pemburu yang baik, Dewa Beruang mau menampakkan dirinya untuk dipanah atau ditangkap, seperti dalam kutipan di atas. Moral ceritanya tidak saja merupakan keharusan bagi pemburu untuk berbuat baik jika ingin selalu berhasil, tetapi juga masyarakat Ainu secara keseluruhan perlu taat melakukan persembahan kepada Dewa Beruang agar dapat hidup sejahtera.
Dalam bagian berikut, cerita mengisahkan bagaimana pemburu memanah tokoh "aku" (Dewa Beruang) dan pada akhirnya mati. Beruang itu disembelih, dagingnya dipisahkan, yang disisakan hanyalah kulit dan kepalanya yang dibawa ke desa untuk diupacarai dalam ritual iomante. Berikut penggalan kisah prosesi iomante yang dimulai oleh pemburu dengan melaporkan kedatangan Dewa Beruang (yang berhasil ditangkap) kepada Dewa Api.

夕暮れ近くアイヌは家に着き、外の祭壇にわたしを置くと 家の中にはいって、火の神に、わたしが客としてきているこ とを知らせました (Kayano, 1993:30).

Terjemahan:

Aku sampai di rumah orang Ainu sore hari, Aku diletakkan di altar bagian luar, lalu manusia melaporkan kedatanganku kepada Dewa Api.

Rincian narasi ritual iomante dalam cerita ini juga terlihat 
pada penekanan adegan roh beruang menikmati persembahan berupa sake dan kue. Juga dilukiskan bagian ritual ketika manusia juga memperdengarkan cerita yukar (saga) yang sangat menarik sehingga tokoh aku ini (Sang Beruang) diceritakan berulang-ulang kembali ke rumah yang sama untuk memberikan anugerah. Secara semiotika, tokoh beruang sebagai ikon dalam cerita, memiliki makna denotatif sebagai binatang berkaki empat yang bisa bertahan hidup dalam musim dingin. Secara konotatif, beruang ini adalah simbol dewa, jadi dia bukan sekadar binatang berkaki empat yang bisa hidup di salju tebal, tetapi merupakan jemaan dewa atau kamui. Tinjauan pemaknaan semiotika level tiga memungkinkan untuk menegaskan bahwa aneka ritual dan persembahan lewat iomante dalam cerita rakyat Ainu merupakan pemitosan nilai-nilai sistem kepercayaan. Dengan kata lain, cerita rakyat menjadi wahana masyarakat Ainu untuk melakukan ideologisasi ajaran kepercayaan mereka. Untuk mendapatkan kehidupan yang penuh berkah, warga Ainu wajib melaksanakan ritual iomante, tanpa ritual itu, beruang tidak akan mau tampil di depan pemburu untuk diburu, dipanah, dan disembelih dengan dagingnya dijadikan lauk dan bulunya dijadikan bahan sandang.

Salah satu prosesi yang tidak kalah penting dari upacara iomante adalah pembacaan cerita yukar.

また、熊をとつたときは、ユカラを最初から語つて、話がお もしろくなつたところでやめなさい。つづきの話を聞きた さに、熊の神はまたアイヌのところへ何度も何度もお客と してやってくるでしょう(Kayano, 1993:125).

\section{Terjemahan:}

Selain itu, ketika mendapatkan beruang, ceritakanlah yukar dari awal, tetapi ketika cerita sudah menjadi menarik, maka berhentilah di sana, maka Dewa Beruang akan datang, datang, dan datang lagi turun ke dunia manusia.

Pada kisah Himana Konabe ('Panci Kecil yang Memiliki Waktu Luang') dan juga cerita Bimbou Ainu to Yukar ('Manusia Miskin dan Cerita Saga') diceritakan bagaimana cara agar Dewa Beruang berkunjung terus ke tempat manusia. Salah satunya adalah dengan menghibur Dewa Beruang pada saat perayaan iomante dengan yukar atau saga, sebuah jenis cerita Ainu. Ahli antropologi Ohnuki-Tierney pernah memperkirakan bahwa masyarakat Ainu memiliki lebih dari 27 jenis pertunjukan lisan (Strong, 2011:6). Di antara itu, yukar adalah salah satu jenis pertunjukan tradisi lisan. Yukar diceritakan dari awal dan cerita sengaja diberhentikan oleh sang pencerita pada saat cerita mulai menarik. Teknik penceritaan penghentian saat klimaks atau momen menarik seperti itu dipercaya akan membuat Dewa Beruang merasa penasaran akan kelanjutan ceritanya. Dengan demikian Dewa Beruang akan berkeinginan datang dan datang lagi. Pemburu yang bermoral dan pencerita yukar yang pandai menghentikan cerita saat klimaks itu merupakan dua hal yang membuat beruang akan datang.

Istilah iomante, inau, yukar, dan sake yang muncul berulang dalam cerita di atas secara semiotika tidak saja memiliki makna denotatif, tetapi juga makna kiasan yang merefleksikan hubungan resiprokal antara Ainu dan para dewa. Resiprokalitas hubungan Dewa Beruang dengan Ainu terlihat pada Dewa Beruang turun ke bumi untuk mendapat ritual iomante, dan manusia tulus-ikhlas menggelar iomante agar terus dibantu Dewa Beruang. Secara mitologis, cerita rakyat Ainu mengandung ajaran-ajaran untuk mengukuhkan ideologi sistem kepercayaan Ainu. Tanda-tanda dalam cerita itu bisa dimaknai sebagai kias bahwa perbuatan baik dan pelaksanaan unsur ritual iomante yang baik, di satu pihak merupakan simbol dari hubungan yang baik antara manusia dengan dewa, yang berimplikasi pada kesejahteraan hidup manusia, dalam hal ini etnik Ainu.

Secara denotatif, beruang adalah binatang; secara konotatif dan mitologis, beruang adalah jelmaan dewa. Dewa beruang bisa menjadi penolong atau pengacau jika kepadanya tidak dilaksanakan upacara yang semestinya. Beruang menurut kepercayaan masyarakat Ainu adalah dewa yang kedudukannya tinggi yang datang ke dunia dalam wujudnya sebagai binatang. Jika masyarakat Ainu menangkap beruang, mereka harus membuat upacara yang disebut iomante, yaitu ritual pengiriman arwah beruang untuk kembali ke alam dewa (Strong, 2011:69)

Salah satu pengetahuan mengenai upacara iomante juga disiratkan pada cerita berjudul Monoshiri Roujin ('Orang Tua yang Serba Tahu'). Pada awal cerita diketahui bahwa ada sepasang suami istri yang memelihara anak beruang di sebuah kandang di samping rumahnya. Pada akhir cerita diketahui bahwa wujud asli anak beruang tersebut adalah kappa. Wujud tersebut membuat penghuni rumah merasa ketakutan.

ふたりは恐ろしさのあまり、ふるえながら見ていると、熊の 姿でえさえを食つていた化け物は、いつのまにか河童の 姿になって眠つているのです(Kayano, 1993:161—162).

\section{Terjemahan:}

Kami sangat ketakutan, melihatnya sambil gemetar, wujud anak beruang yang sedang makan tadi entah kapan berubah menjadi sosok siluman kappa yang sedang tertidur.

Kappa adalah sejenis makhluk air dalam mitologi Jepang. Siluman kappa itu sengaja berubah menjadi beruang agar dapat hidup dekat manusia dan lebih mudah untuk memangsa manusia. Dalam kepercayaan masyarakat Ainu, jika mereka menangkap seekor anak beruang, biasanya dipelihara sekitar setahun sebelum dibuatkan upacara iomante (Walker, 2001:115). Hal ini rupanya diketahui oleh siluman kappa. Untuk dekat dengan mangsanya, yaitu manusia, ia mengubah wujud silumannya menjadi seekor 
beruang agar dipelihara oleh manusia. Tokoh "aku" yang merupakan seorang wanita yang memelihara anak beruang tersebut meminta petunjuk kepada orang tua yang mengetahui cara mengalahkan kappa itu. Pada kisah Monoshiri Roujin siluman kappa dapat ditaklukkan dengan benang pelindung, mamori himo. Siluman dewa jahat atau buruk tersebut pun dikirim ke dunia dewa.

悪い神を送る祭壇を作りはじめました

(Kayano, 1993:163).

\section{Terjemahan:}

Kami pun mulai membuat altar persembahan untuk mengirimkan dewa yang jahat itu.

Pada cerita Monoshiri Roujin tokoh aku pada awalnya menggunakan istilah bakemono atau siluman, tetapi ketika upacara pengiriman arwah, tokoh aku menggunakan istilah warui kami ('dewa yang jahat') dan mendapat perlakuan yang sama ketika mengirim arwah dewa yang jahat tersebut. Maksud masyarakat Ainu mempersembahkan inau, sake, dan persembahan lainnya kepada dewa yang jahat, agar dewa tersebut kembali ke alam dewa dan tidak mengganggu manusia lagi.

Beruang yang melakukan kekacauan di dunia manusia terdapat dalam cerita Mimiwa no Katahou ('Sebelah bagian Anting-Anting'). Beruang diceritakan mengintai manusia dan ingin memangsa manusia.

「近くに化け物熊がふたりをねらってひそんでい る、早く家へ帰りなさい。いつの日かまた会うとき まで」(Kayano, 1993:169).

Terjemahan:

Seekor siluman beruang sedang bersembunyi di dekat sini dan menjadikan kalian berdua targetnya, segera kembali ke rumah. Sampai bertemu lagi suatu hari nanti.

Cerita ini mengisahkan tokoh laki-laki (tokoh utama) memberikan informasi mengenai keberadaan beruang kepada seorang laki-laki dan seorang perempuan yang sedang melintas di dekat hutan. Ungkapan "itsu no hi ka mata au toki made", yang berisi harapan 'semoga bertemu lagi' itu, disertai dengan pemberian sebelah anting-anting oleh tokoh utama kepada orang yang baru ditemuinya tersebut. Secara semiotika, anting-anting itu merupakan simbol untuk menandai bahwa mereka pernah berjumpa dan tanda untuk konfirmasi untuk pertemuan kelak. Pada akhir cerita, kedua orang itu pun mencari penolongnya, yaitu pemilik sebelah bagian anting-anting tersebut untuk mengucapkan terima kasih.

Kemunculan siluman beruang atau beruang yang mengganggu manusia seperti yang muncul dalam cerita Mimiwa no Katahou, menurut kepercayaan Ainu disebabkan karena manusia tidak merawat beruang dengan ritual dan sesaji yang tepat. Dalam kepercayaan masyarakat Ainu, monster beruang disebut ararush. Ararush ditakuti karena beruang tersebut akan menguntit dan menyerang manusia, membendung sungai untuk memakan seluruh salmon yang ada, dan menakut-nakuti ternak rusa dan hewan lainnya (Askenazi, 2008:64). Pada cerita Mimiwa no Katahou beruang yang membuat onar itu akhirnya dapat dikalahkan manusia dengan kerja sama. Bukan kekalahannya ini yang penting, tetapi pesan cerita bahwa beruang dapat melakukan keonaran jika masyarakat tidak melakukan ritual yang baik untuk (Dewa) Beruang. Jika disimak dari teori semiotika Barthes, cerita-cerita Ainu tentang beruang merupakan mitos yang dipercaya masyarakat.

\section{TRADISI IOMANTE: ANTARA TEKS DAN PRAKTIK}

Walaupun sempat dilarang oleh pemerintah Jepang dengan alasan berisi tindakan membunuh beruang secara kejam, ritual iomante tetap dilaksanakan karena bagi Ainu ritual ini merupakan 'korban suci beruang' (Walker, 2001:114) atau pengembalian roh beruang ke alam Dewa. Di luar pelaksanaan ritual dalam praktik, terdapat juga teks mengenai iomante dalam cerita rakyat seperti yang dibahas di atas.

Tentang pelaksanaan ritual ini, ada beberapa informasi yang terpisah yang menunjukkan bahwa paling tidak ritual ini pernah terlaksana sampai 1956, seperti dimuat dalam surat kabar Asahi Shimbun (16 Juli 2017) dalam artikel berjudul "Rare Ainu Bear Sacrifice Ritual Photos Found after 61 Years" [Foto-foto Upacara Ritual Beruang yang Langka Ditemukan sesudah 61 Tahun] (Watanabe, 2017:1-2). Artikel ini menunjukkan bahwa ritual korban suci beruang merupakan upacara yang langka. Memang, dalam suatu waktu di masa lalu, ritual ini tidak selalu bisa dilaksanakan. Pemertahanan ritual tradisional juga bersifat berbeda dari tempat ke tempat (Yamada, 1999:94).

Ada juga data audio-visual yang menunjukkan bahwa ritual ini ada terlaksana awal 1930-an. Hal ini misalnya bisa dilihat dalam video berjudul "The Ainu Bear Ceremony" yang dibuat antropolog Dr. N.G. Munro menggambarkan pelaksanaan iomante tahun 1931. Narator dalam video ini menjelaskan bahwa ritual korban suci beruang ini adalah upacara keagamaan penting bagi Ainu. Narator juga menegaskan bahwa ritual ini tidak lagi dilaksanakan. Namun, jika ungkapan narator video itu dikontraskan dengan bukti yang ada dari tahun 1956, jelas pernyataan narrator kurang akurat, karena laporan koran Asahi Shimbun menunjukkan iomante digelar tahun 1956.

Dalam video tampak adegan masyarakat menggelar iomante yang sama dengan deskripsi dalam cerita rakyat. Video melukiskan pemasangan tengkorak beruang di tombak yang dipancangkan di depan rumah, juga ada adegan beruang kecil yang dipelihara dalam kendang sebelum dis- 
embelih untuk ritual. Pemeliharaan itu sampai bertahun-tahun hingga mencapai usai beruang cukup untuk dipotong untuk ritual. Kepala beruang yang dipenggal dari tubuhnya dipajang di sekitar sesajen, dan tetua Ainu melakukan persembahyangan. Pesta makanan dan tari-tariamn yang melibatkan laki-laki dan perempuan juga ditampilkan dalam video ini. Rangkaian ritual dilakukan untuk membuat roh beruang merasa riang dan mereka bersedia datang lagi ke alam manusia lewat beruang lain untuk diburu dan dibunuh oleh manusia. Rangkaian ritual iomante dalam video sebagai bentuk praktik dan dalam teks pada dasarnya sama, artinya mengandung unsur inti dan pesan yang sama.

Kesamaan esensi narasi teks dan film merefleksikan praktek ritual iomante di masyarakat Ainu. Bukti ini menunjukkan iomante dijunjung tinggi masyarakat Ainu, mereka berusaha melaksanakan ritual yang merupakan bagian dari tradisinya. Belakangan, tahun 1970-an dan tahun 1985, iomante digelar untuk memberikan edukasi kepada generasi muda Ainu. Askenazi (2008:63) dalam bukunya Handbook of Japanese Mythology menjelaskan bahwa "kamui and the Ainu have a reciprocal relationship" ("kamui dengan Ainu memiliki hubungan timbal-balik'). Hal ini menunjukkan penambahan nilai pelaksanaan ritual, selain untuk pelaksanaan tradisi sistem kepercayaan, iomante juga untuk edukasi budaya bagi generasi muda Ainu.

Perkembangan lain menunjukkan bahwa iomante juga dijadikan bagian dari festival Ainu yang berfungsi untuk promosi pariwisata etnik. Hokkaido Ainu Festival dilaksanakan pertama kali tahun 1963 oleh Ainu Tourist Association di Asahikawa. Festival ini diisi dengan kegiatan seperti konferensi, resitasi (penembangan) yukar, ritual iomante, dan tari-tarian. Tidak kurang dari dua ratus orang Ainu terlibat dalam festival ini dan disaksikan oleh lebih dari dua ratus ribu penonton. Selain manfaat ekonomi, festival ini menjadi ajang bagi Ainu untuk berkumpul menunjukkan kesenian mereka. Usaha serupa dilakukan tahun 1989 berupa Ainu Cultural Festival tahunan, memamerkan berbagai produk seni budaya Ainu (Hiwasaki, 2000:407). Pelaksanaan iomante dalam berbagai bentuknya jelas merupakan praktik dalam melestarikan budaya Ainu, dalam hal ini ritual pengembalian roh beruang ke alam Dewa.

\section{SIMPULAN}

Artikel ini menganalisis cerita rakyat Ainu tentang ritual iomante kaitannya dengan narasi teks dengan praktik tradisi di masyarakat. Hal analisis menunjukkan bahwa narasi ritual iomante (pengembalian roh beruang ke alam dewa) yang terdapat dalam cerita rakyat dan deskripsi sumber lain seperti foto dan video menunjukkan persamaan. Secara sosiologi sastra, cerita rakyat tentang iomante merupakan refleksi dari pelaksanaan tradisi masyarakat Ainu yang digelar sampai sekarang. Secara semiotika, narasi ritual iomante dalam cerita rakyat dan dalam praktik kehidupan sosial juga sama-sama merupakan wahana bagi masyarakat Ainu untuk memperkuat sistem kepercayaan mereka tentang Dewa Beruang. Dengan kata lain, cerita rakyat merupakan wahana untuk melestarikan ideologi sistem kepercayaan atau merupakan pandangan dunia Ainu terhadap sistem kepercayaan mereka sebagai sesuatu yang wajib digelar dan dilestarikan.

Dalam perkembangan berikutnya, pelaksanaan ritual iomante tidak saja berperan untuk pelestarian tradisi, edukasi lintas generasi, tetapi juga sebagai pendukung festival dalam rangka promosi pariwisata. Penambahan makna iomante ini turut melestarikan ritual korban suci beruang dalam masyarakat Ainu yang terus berubah sesuai dengan perkembangan zaman. Antara teks cerita rakyat iomante dan praktik pelaksanaan upacara iomante dengan berbagai transformasinya memiliki peran yang saling menguatkan untuk melestarikan aspek budaya Ainu lintas generasi. Dalam tahap ini, cerita rakyat, film, video tentang ritual iomante dapat dikatakan dokumen sosial budaya yang menjadi landasan dan memperkuat program pelestarian budaya Ainu.

\section{DAFTAR RUJUKAN}

Akino, Shigeki. (1999), "Spirit Sending Ceremony" dalam dalam Ainu Spirit of a Northern People. William W. Fitzhugh dan Chisato O. Dubreuil (ed.). Washington: National Museum of Natural History in association with University of Washington Press, pp. 248-255.

Askenazi, Michael. (2008), Hand Book of Japanese Mythology. New York: Oxford University Press.

Barthes, Roland. (1962), Elements of Semiology. New York: Hill and Wang.

Barthes, Roland. (1977), Image-Music-Text, Essays Selected and Translated by Stephen Heat. Glasgow: Fontana/ Collin.

Batchelor, John. (1889), The Speciments of Ainu Folklore. USA:! Library of Alexandria.

Batchelor, John. (1892), The Ainu of Japan: The Religion, Superstitions, and General History of The Hairy Aborigines of Japan. London: Religious Tract Society.

Batchelor, John. (1901), The Ainu and Their Folklore. Tokyo: Kyoubunkan.

Chandler, Daniel. (2002), Semiotics, The Basics. London: Routledge.

Damono, Sapardi Djoko. (1978), Sosiologi Sastra: Sebuah Pengantar Ringkas. Jakarta: Pusat Pembinaan dan Pengembangan Bahasa, Departemen Pendidikan dan Kebudayaan. 
Davidson, Deborah. (2007), “Two Ainu Folktales”, dalam World Literature Today, Vol. 81, No. 5 (Sep. - Oct., 2007), hlm. 26-28.

Fitzhugh, William W. (1999), “Ainu Ethnicity: A History", dalam Ainu Spirit of a Northern People. William W. Fitzhugh dan Chisato O. Dubreuil (ed.). Washington: National Museum of Natural History in association with University of Washington Press, pp. 9-27.

Kayano, Shigeru. 1993. Ainu Mukashi Banashi: Hito Tsubu no Satchiporo. Tokyo: Heibonsha.

Kindaichi, Kyōsuke and Minori Yoshida. (1949), “The Concepts behind the Ainu Bear Festival (Kumamatsuri)", Southwestern Journal of Anthropology, Vol. 5, No. 4 (Winter, 1949), pp. 345-350.

Kitagawa, Joseph M. (1961), “Ainu bear Festival (Iyomante)" History of Religions, Vol. 1, No. 1 (Summer, 1961), pp. 95-151.

Ohnuki-Tierney, E. 1981. Illness and Healing among the Sakhalin Ainu: A Symbolic Interpretation. Cambridge: Cambridge University Press.

Renner, Nate. (2012). “Ainu Ceremonial Music and Dance: "Restored" and Recontextualized", Volume 39, Number 1 (2012), pp. 208-225.

Sari, Ida Ayu Laksmita. (2019), “Kajian Komparatif Wacana Kearifan Lokal Cerita Rakyat Bali Aga dan Ainu Jepang”, disertasi Prodi Doktor Linguistik, Universitas Udayana.

Sjöberg, Katarina V. 2013. The Return of the Ainu Cultural Mobilization and the Practice of Ethnicity in Japan. London: Routledge.

Strong, Sarah M. (2011), Ainu Spirits Singing: The Living World of Chiri Yukie's Ainu Shin'yushu. Honolulu: University of Hawai'i Press.

Teeuw, A. (1984). Sastra dan Ilmu Sastra: Pengantar Teori Sastra. Jakarta: Dunia. Pustaka Jaya.

Utagawa, Hiroshi. (1999) "The Archeology of Iyomante", dalam Ainu Spirit of a Northern People. William W. Fitzhugh dan Chisato O. Dubreuil (ed.). Washington: National Museum of Natural History in association with University of Washington Press, pp. 256-260.

Walker, Brett L. (2001), The conquest of Ainu lands: ecology and culture in Japanese expansion, 1590-1800. Berkeley Los Angeles London: University of California Press.
Yamada, Takako. (1999), An Anthropology of Animism and Shamanism. Budapest: Akadémiai Kiadó. 